\title{
Teaching Study Based on Project Design and Independent Learning
}

\author{
Cunyuan $\mathrm{Mu}$ \\ Design art school \\ Shenyang Jianzhu University \\ Shenyang China \\ ysyz@sjzu.edu.cn
}

\author{
Xuemin Liu \\ Design art school \\ Shenyang Jianzhu University \\ Shenyang China \\ 275968878@qq.com
}

\begin{abstract}
Students are the subject in the learning activities, and only the subjective initiative of students brought into full play can learn truly learned and genuinely talented. The teaching reform is an important task for training excellent engineers. Students' independent study is a purposive study under the direction of teachers. This way of study should be in accordance with the project training, and the students, under the direction of teachers, should be aware to set a reasonable personal objective of independent learning. Through the entire period of academic learning, students should carry out self identification, self selection, self training, including self evaluation and self adjustment.
\end{abstract}

Keywords-Project item; independent learning; ability cultivation; teaching design

\section{INTRODUCTION}

With the development of national reform and opening up, Chinese higher education is in the reform climax of the education system and educational means. Traditionally, everyone notices "how to teach", because those teachers are teaching the first principal. In fact, another aspect is that can be easily ignored - "how to learn". This is also an important reform topic in higher education, in particular, project-based "how to learn", because the student is the main body of teaching and learning process [1]. How to learn, of course, is a task for teachers, but the bottom line is that the students their fundamental task, it directly affects the quality of learning. College students should also be able to do well in their own independent learning.

\section{INDEPENDENCE LEARNING AND ITS CHARACTERISTICS}

Independence learning in terms of intrinsic quality of learning, as opposed to "passive", "machine learning", it is actually no cognitive monitoring learning, it is on their own learning and learning task requirements. It can proactively adjust their process of learning strategies. Independence learning requires the student conscious awareness to learn what and how [2]. If a student can identify the following characteristics before the learning activities, can we say that his study is independent learning:(1) Learning goals, (2) Learning plans, (3) Specific learning preparation, (4) Able to progress in learning activities and learning of the selfmonitoring, (5) Self-examination, self-summary results, selfevaluation and self-recovery in learning activities.

\section{WAYS OF PROMOTING STUDENTS' INDEPENDENCE LEARNING}

\section{A. Guide student to develop an understanding and discovery}

In teaching activity teachers help students to construct knowledge system, rather than copying knowledge. Students don't know the knowledge that predecessors left us. Teachers should guide them to develop an understanding and discovery. It is critical students to find in the learning. When student raised valuable questions, teachers should be guided, let the students know what problems the valuable. It is good for students to discover in cultivating theirs interest in and cultivate the habit of asking questions. For example, when you talk about principles of perspective, teacher should make student clear that the camera is equivalent to using the principles of observing phenomena in one eye, then prompts the student observations if two eyes, three eyes observing what would happen, at the same time, ask students read three dimensional scanning principle, etc. Under these circumstances, some students understand the reason why the scientists use three cameras take the Moon surface topography on Chang E, 2nd. Teachers should seize this favorable opportunity, guide students to apply experimental, query information, learn new knowledge and innovation, which is to help students to step into the excellent means of autonomous learning tracks [3].

\section{B. Develop students' capacity to collect and process information}

The ability to collect and process information is essential for survival and development in modern society, and one of the ways to promote students' autonomous learning. Textbooks and other reference books is the important channel for students to gain information, but not the only channel. Teacher should strengthen guidance, enabling students to develop multi-faceted ability to get information. Through the reading information on the internet, experiments or exploration activities, allow students to read scientific journals, students can access to current and relevant information. Teachers should point out to students in a timely manner to get the latest information about channels, help the student gradually into autonomous learning track.

\section{Learn to introspection and self-summary}

Within certain stages of the student's own learning reflection and self-summary, based on his collection of 
materials preparation of ask and answer by yourself, solving, independent learning and enabling students to learn effective ways to organize information.

\section{Recognition of student diversity according to his aptitude}

In order different students have different professional development in their professional learning, teachers should fully understand the students, recognize and pay attention to students' individual differences, discover the uniqueness of each student, of particular interest to students in accordance with their aptitude. For example, for students who prefer hands-on, teachers can schedule them for pilot projects, for students who prefer life and social issues, teachers should encourage them to take them to do research, and for the students who are interested in concept and regularity of things, teachers should guide them to make some rational thinking and exploration.

\section{THE BASIC FORMS OF STUDENTS' AUTONOMOUS LEARNING}

\section{A. Carrying out inquiry teaching activities}

Scientific research is an important way of teaching and an important way of learning. In scientific inquiry, students as scientists do research, learn knowledge and skills on their own and experience the joy of learning. In carrying out exploratory activities, teachers must do the following work:

1) Students are encouraged to participate in actively scientific inquiry. Scientific exploration of student is learning activities by participation. Teachers should encourage students hands-on and use their minds, through independent exploration activities, to learn about concepts and laws and experience the joy of scientific inquiry. In the process of exploring, to help students to overcome ideological barriers, such as fear of error, trouble, while difficult to give guidance where appropriate to enable students to successfully participate in scientific inquiry activity[4-5]. This allows students to joy the success by experience, to prevent negative psychological effects from multiple setbacks. Teachers should not just no less meaningful questions raised by students or manifestly incorrect conjecture, should be fully affirmed the students but also to point out the correct method of composition, in order to enable students to see their achievements and strengthen their participating in courage and initiative.

2) Supervising teacher select the appropriate inquiry activities. Teachers should be combined with the actual situation of the related research projects and students' to design some research activities. Research projects should be able to stimulate the interest of students in order to achieve the purpose of cultivating students' interests in scienceloving feelings. In addition, students learning scientific inquiry should be from simple to complex, step by step, when students are in trouble, teachers give students tips, in order to keep the students continue to explore with confidence.

3) Importance to exchanges and cooperation in inquiry activity. Project research activities should be grouped and each group of two or three students. Teachers should clear division of labor within the group, to give full play to the enthusiasm of students in inquiry activity. Cannot be a minority student to monopolize the problem solve.

\section{B. Guide students through hands-on activities}

This activity is designed to enable students to learn in a more scientific way of knowledge, with particular emphasis on the cultivation of students' learning methods, ways of thinking, motivation. It has the following characteristics: Emphasis on hands-on activities, emphasis on students' active learning, emphasis on learning, attach importance to developing learning methods, ways of thinking and attitudes towards learning. Promoting cooperation and Exchange, in other words, do ask a question-experimental observation records-explains-discussion-conclusion-expression statement. Hands-on activities using method of learning, questioning, research and experimentation, rather than rote learning factual knowledge, emphasizing the students hands-on experiments and thoughts, and to understand the experimental results and discussions. Students need to learn how to do a personal record, to plan and report on what they have learned, practice collaboration, charting, and render some form or report findings. Therefore, in this activity students have a certain degree of autonomy.

\section{Take full advantage of Internet learning environment}

From basic graphic design, various design software and product design, accompanied by improvement of technology in the teaching, computer networking technology has become an important way of learning. Through various modern means students can get information from media, mobility activities to reflect more of the senses, and then their learning styles will be further improved.

\section{Small study on after-school programs}

Small study on after-school programs at home and abroad has become an important trend of cultivating practical capability of engineering of students. Students are very interested in these small after-school programs. Upon completion of small after-school programs, student-oriented cooperation and exchange. This will be another important way to improve the way students learn. Small extracurricular research project has the following characteristics:

1) It needs to have a more practical problem and the problems for the students to have a scope for exploration and reflection space.

2) Students to conduct a small survey are researchoriented extracurricular projects, the process is very important.

3) Students with certain autonomy and teachers play the guiding role. It needs the transformation of students' 
learning style, construction aims to develop students' innovative consciousness and practical ability of learning, helping students to enter autonomous learning track. These are the problems in the reform of teaching, but also the general issue of teachers' teaching idea change.

\section{LEARNING ENVIRONMENT DESIGN}

Take "product design" course of independent learning as an example, combined with existing conditions of teaching in schools, we design 15 learning environment fields of study for "product design", they are market investigation, user's needs, functional design, shape-design, impression drawing, color scheme, ergonomic design, detail design, assembly drawing, part drawing, functional test, revised design, rapid prototyping, user experience, completion of the overall design. Entire course in a learning environment designed to project as carrier and covers all the content of the course.

Project is based working process systematization, the choice between the projects is important, and each individual item could not be dissociated from each other. The project should be sustainable and systemic. Each project has developed in specific situation that correspond to specific parts for the examples to explain knowledge, rather than traditional teaching software menu function list. Repeat step here, not the content. As students become the principal in their learning, enhancing students' professional quality intensive professional post ability and cultivation of core competence becomes more and more important.

\section{TEACHING DESIGN}

In the course of teaching, each teaching situation in the form is completed according to information, decision making, planning, implementation, checking, assessing. Here takes shaft design as an example of learning situations in teaching process.

\section{A. Information}

Questions to the front, teachers issued project assignments before class. Students gather information required for project planning and implementation. This is good for increasing students' confidence and logical thinking ability, strengthen their learning autonomy.

\section{B. Planning and decision making}

Students discuss and formulate project implementation plan in group according to assignments, teachers responsible for the inspection, examine the feasibility give the team changes, confirm the final programme of work tasks, give the group changes and determine the final programme of work tasks.

\section{Process implementation}

Students perform tasks in a cooperative manner according to plan. Team members have a clear division of tasks, responsible for analysis of drawings, discuss the development of product modeling steps and feature generation. Teachers are responsible for answering questions in the supervision. Here student-led, teachers just play a guiding role.

\section{Inspection examine}

Students evaluate by themselves, groups evaluate each other, and teacher gives common assessment. Eventually each group forms a complete report. Throughout the process of teaching, students' learning autonomous is the main form, unlike traditional one-sided teaching. Under the teacher's guide, students study project and practice on access to information independently, and enable students to each other through a group inspired and make progress together. Based working process systematization of design practice, students can get the foundation of sustainable development.

\section{CONCLUSION}

Based on process-oriented curriculum, instructional design is the key to achieving the targets. The selection is important of all aspects involved in the process, teaching materials and teaching aids, equipment, facilities, teaching sites make effective planning, organization, plan and develop class plans, equipment used, such as lesson plans etc. At the same time, teachers should also pay attention to the reform and development of teaching method and means, by induction, deduction, analysis, synthesis, and other traditional teaching methods to the project teaching method of teaching law, case law, simulation, role play, leading grammar conversions. Teaching structure and manner should convert to working program, integrate the theory and practice. Teaching site consist of theoretical classroom should convert to multi-functional laboratory, where students can discussions, do experiments and theoretical and practical teaching.

Reasonably equipped with teachers is also the key point. Engineering training-oriented curriculum needs higher demands on teachers. To train high level of engineers who understand theory and well technical personnel works, needs the teachers thought enough attention on cultivation of excellent engineers and set theory in teaching, technology and skills all in one.

\section{REFERENCES}

[1] LIU Jun, WANG Ye, YANG Hui-qin and SHI Zhen, "Mechatronical Comprehensive Experiment Based on Engineering Projects," Research and Exploration in Laboratory. Vol. 31 No. 8, pp. 128-130, Aug. 2012.

[2] Lin Jian, Restudy on the Professional Training Program of "A Plan for Educating and Training Outstanding Engineers," Research in Higher Education of Engineering, vol. 4, pp. 10-17, Nov. 2010.

[3] Zhu Gaofeng, Discussion on Engineering Education Ideas. Research in Higher Education of Engineering, vol. 1, pp.1-5, Jan 2011.

[4] Dong Lulu, How to Develop Creativeness and Independent Language Learning Ability, Journal of Shanxi University (Philosophy \& Social Science), Vol.23 No.3, pp.84-86, Aug.,2000.

[5] Shen Li and Li Guiyang, A Design Improving Independent Learning in the Network-instruction System, Journal of Sichuan Normal University (Natural Science), Vol.27,No.3, pp 328-330, May,2004. 